\title{
Advanced glycation endproducts, dityrosine and arginine transporter dysfunction in autism - a source of biomarkers for clinical diagnosis
}

Attia Anwar ${ }^{1+}$, Provvidenza Maria Abruzzo ${ }^{2,4 \dagger}$, Sabah Pasha ${ }^{1}$, Kashif Rajpoot ${ }^{3}$, Alessandra Bolotta $^{2,4}$, Alessandro Ghezzo ${ }^{2}$, Marina Marini ${ }^{2,4}$, Annio Posar ${ }^{5,6}$, Paola Visconti ${ }^{5}$, Paul J. Thornalley ${ }^{1,7}$ and Naila Rabbani $i^{1,7,8^{*}}$

\begin{abstract}
Background: Clinical chemistry tests for autism spectrum disorder (ASD) are currently unavailable. The aim of this study was to explore the diagnostic utility of proteotoxic biomarkers in plasma and urine, plasma protein glycation, oxidation, and nitration adducts, and related glycated, oxidized, and nitrated amino acids (free adducts), for the clinical diagnosis of ASD.

Methods: Thirty-eight children with ASD (29 male, 9 female; age $7.6 \pm 2.0$ years) and 31 age-matched healthy controls ( 23 males, 8 females; $8.6 \pm 2.0$ years) were recruited for this study. Plasma protein glycation, oxidation, and nitration adducts and amino acid metabolome in plasma and urine were determined by stable isotopic dilution analysis liquid chromatography-tandem mass spectrometry. Machine learning methods were then employed to explore and optimize combinations of analyte data for ASD diagnosis.

Results: We found that children with ASD had increased advanced glycation endproducts (AGEs), $N_{\varepsilon}$-carboxymethyllysine (CML) and $N_{\omega}$-carboxymethylarginine (CMA), and increased oxidation damage marker, dityrosine (DT), in plasma protein, with respect to healthy controls. We also found that children with ASD had increased CMA free adduct in plasma ultrafiltrate and increased urinary excretion of oxidation free adducts, alpha-aminoadipic semialdehyde and glutamic semialdehyde. From study of renal handling of amino acids, we found that children with ASD had decreased renal clearance of arginine and CMA with respect to healthy controls. Algorithms to discriminate between ASD and healthy controls gave strong diagnostic performance with features: plasma protein AGES—CML, CMA—and 3-deoxyglucosonederived hydroimidazolone, and oxidative damage marker, DT. The sensitivity, specificity, and receiver operating characteristic area-under-the-curve were 92\%, 84\%, and 0.94, respectively.

(Continued on next page)
\end{abstract}

\footnotetext{
* Correspondence: n.rabbani@warwick.ac.uk

${ }^{\dagger}$ Equal contributors

'Warwick Medical School, University of Warwick, Clinical Sciences Research Laboratories, University Hospital, Coventry, UK

${ }^{7}$ Zeeman Institute for Systems Biology \& Infectious Disease Epidemiology

Research, Senate House, University of Warwick, Coventry CV4 7AL, UK

Full list of author information is available at the end of the article
} 
(Continued from previous page)

Conclusions: Changes in plasma AGEs were likely indicative of dysfunctional metabolism of dicarbonyl metabolite precursors of AGEs, glyoxal and 3-deoxyglucosone. DT is formed enzymatically by dual oxidase (DUOX); selective increase of DT as an oxidative damage marker implicates increased DUOX activity in ASD possibly linked to impaired gut mucosal immunity. Decreased renal clearance of arginine and CMA in ASD is indicative of increased arginine transporter activity which may be a surrogate marker of disturbance of neuronal availability of amino acids. Data driven combination of these biomarkers perturbed by proteotoxic stress, plasma protein AGEs and DT, gave diagnostic algorithms of high sensitivity and specificity for ASD.

Keywords: Autism spectrum disorder (ASD), Advanced glycation endproducts (AGEs), Oxidative stress, Amino acid metabolome, Machine learning

\section{Background}

Autism spectrum disorders (ASD) are defined as developmental disorders mainly affecting social interactions and range of interests and causing a wide spectrum of other disabilities, such as speech disturbances, repetitive and/or compulsive behaviors, hyperactivity, anxiety, and difficulty to adapt to new environments, with or without cognitive impairment [1]. The high heterogeneity of the clinical presentation makes diagnosis of ASD difficult and uncertain, particularly at the early stages of development. Discovery and development of robust biomarkers for diagnosis and progression of severity of ASD is expected to facilitate earlier diagnosis and intervention. It will also likely reveal new causative factors $[2,3]$. In particular, alteration in the metabolome and specific damaging biochemical modifications may reveal the presence of a shared metabolic impairment in children with an otherwise highly heterogeneous background, thus shedding some light on the etiopathogenesis of ASD. Genetic causes of ASD are evident in about $30-35 \%$ of cases. For the remaining $65-70 \%$ of patients, it is generally agreed that ASD results from the combination of environmental factors with multiple de novo mutations, copy number variation, and rare genetic variants, each possibly lending to additive effects. Environmental factors may also be involved and reflected in epigenetic modifications [4]. Transcriptomic, proteomic, and metabolomic profiling have been proposed for diagnosis of ASD, with diagnostic performance judged by area under-the-curve of receiver operating characteristic (AUROC) plot of 0.73-0.91 [5-7]. It is expected that improved diagnostic performance may be achieved with a relatively small number of biomarker analytes linked to the pathogenic mechanism of ASD.

Impairment of protein homeostasis leading to proteotoxic stress and activation of the unfolded protein response (UPR) has been implicated in ASD [8]. Drivers of impaired protein quality are increased spontaneous modifications by glycation, oxidation, and nitration [9]. Glycation of proteins occurs by spontaneous reaction of proteins with glucose, reactive dicarbonyl metabolites, glyoxal, methylglyoxal (MG), and 3-deoxyglucosone (3-DG), and other saccharides and saccharide derivatives. Protein glycation adducts are classified as early stage glycation adducts-such as $N_{\varepsilon}$-fructosyl-lysine (FL) residues formed by glycation of proteins by glucose-and late-stage adducts, advanced glycation endproducts (AGEs) - such as $N_{\varepsilon}$-carboxymethyl-lysine (CML) and glucosepane (GSP) residues-formed by the degradation of FL residues, hydroimidazolones G-H1, MG-H1, and 3DG-H formed by the modification of arginine residues by glyoxal, MG and 3-DG, respectively, $N_{\omega}$-carboxymethylarginine (CMA)-also formed by the reaction of glyoxal with arginine residues, and methylglyoxal-derived lysine crosslink (MOLD). Protein oxidation occurs by the reaction of proteins with reactive oxygen species (ROS) and is increased in oxidative stress. Examples of protein oxidation adducts are dityrosine (DT), $N$-formylkynurenine (NFK), $\alpha$-aminoadipic semialdehyde (AASA), and glutamic semialdehyde (GSA) residues. Oxidative stress has been implicated as a contributory factor in the development of ASD [10-12]. Increased oxidative damage associated with oxidative stress and neuroinflammation may be common features of ASD in children. Protein nitration occurs by the reaction of proteins with reactive nitrogen species such as peroxynitrite. The main adduct formed by protein nitration is 3-nitrotyrosine (3-NT) residues (Fig. 1). Increased protein damage by these mechanisms may lead to activation of the UPR to counter the proteotoxic threat and related inflammatory response $[13,14]$.

Glycated, oxidized, and nitrated proteins undergo proteolysis to form related glycated, oxidized, and nitrated amino acids-also called glycation, oxidation, and nitration free adducts. Glycated, oxidized, and nitrated amino acids are released into plasma and are excreted in urine. Urinary excretion of glycation, oxidation, and nitration free adducts are approximate measures of whole body fluxes of protein glycation, oxidation, and nitration, respectively. There are also minor contributions to the pool of these metabolites by direct glycation, oxidation, and nitration of amino acids and absorption from food after digestion of damaged proteins therein [9]. Insight into renal handling of amino acids by the kidney is gained by deducing the renal clearance (CL) of amino acids from plasma to urine. For low 


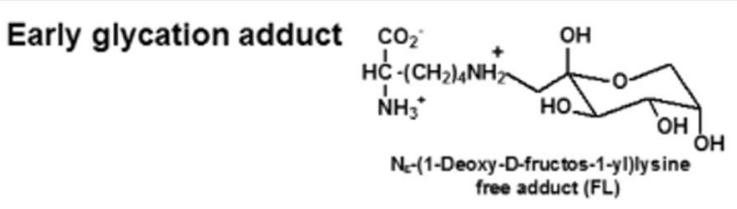

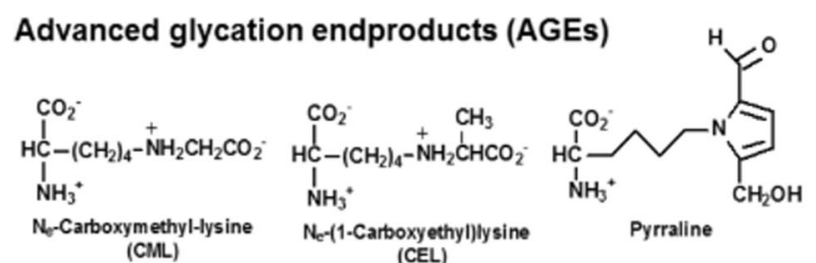
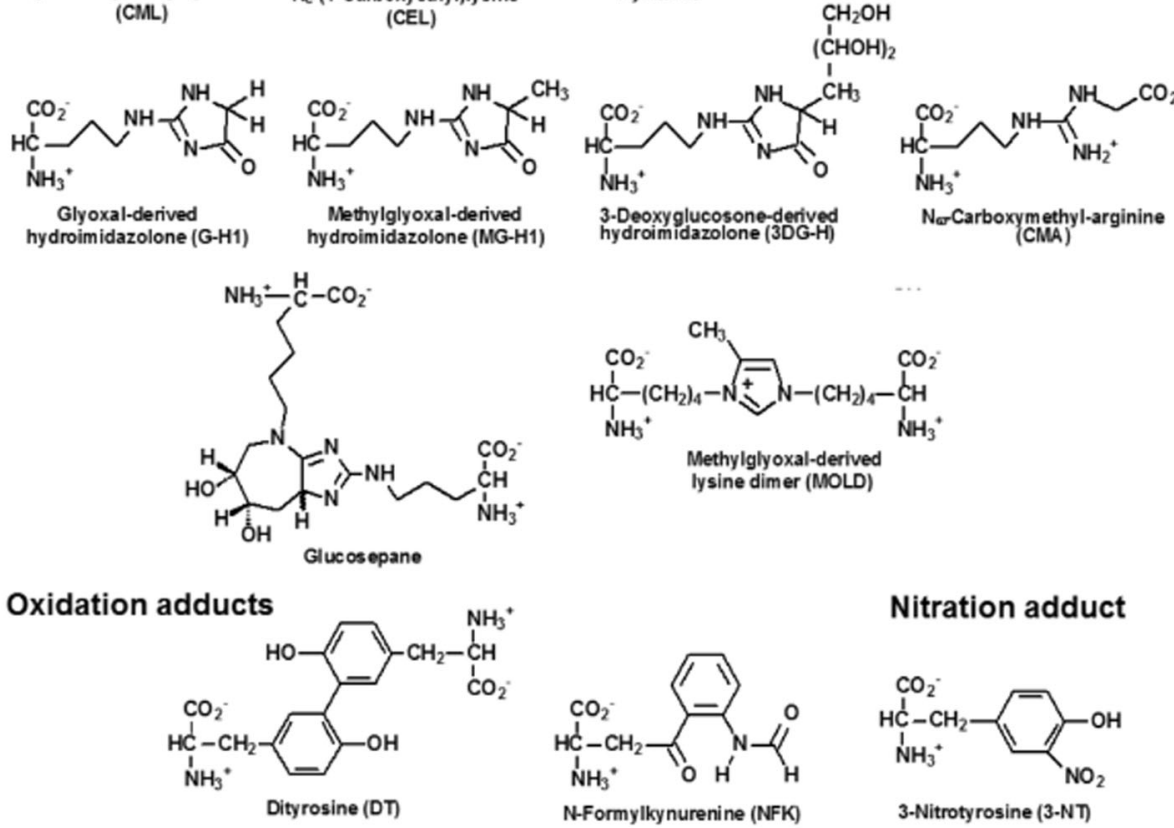

Nitration adduct

N-Formylkynurenine (NFK)
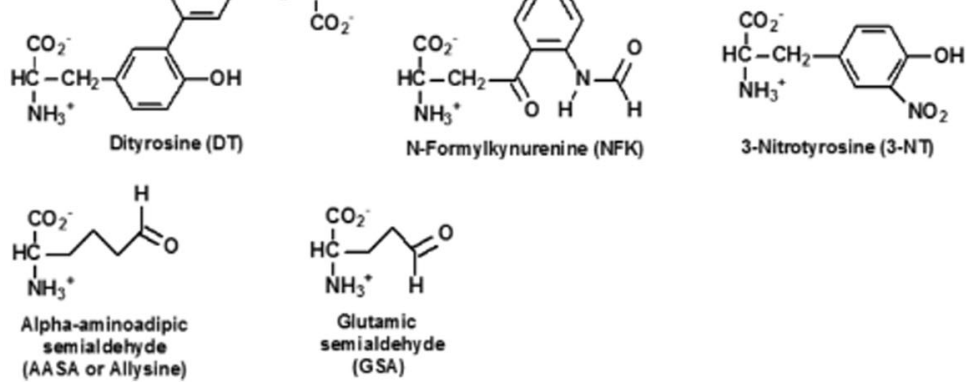

Fig. 1 Protein glycation, oxidation, and nitration free adducts. Ionization status at physiological pH is shown. For related adduct residues of proteins, alpha-amino- $\mathrm{NH}_{3}^{+}$and terminal carboxylate $-\mathrm{CO}_{2}^{-}$groups are moieties of as peptide bonds $-\mathrm{NH}-\mathrm{CO}-$ with amino acid residues immediately before and after in the peptide backbone

molecular weight metabolites such as amino acids, CL is mainly influenced by renal tubule reuptake of amino acids mediated by amino acid membrane transporters. ASD has been previously associated with homozygous mutations in gene solute carrier family 7, member 5 (SLC7A5) which encodes the large neutral amino acid transporter subunit-1 (hLAT-1); and in males, with rare holomorphic variants of cationic amino acid transporter-3 (CAT-3) mediating uptake of arginine, ornithine, and lysine. These transporters mediate amino acid uptake into the cells, including neurons [15].

In this study, we explore the association of proteotoxic damage with ASD by quantifying levels of protein glycation, oxidation, and nitration adducts in plasma protein and related free adducts in plasma and urine of children with ASD and healthy controls. We also quantify the conventional plasma amino acid metabolome [16] and CL of glycation, oxidation, and nitration free adducts and unmodified amino acids. We then explore the diagnostic potential of these biomarkers by development of diagnostic algorithms with optimum combinations of analyte features. We found evidence of increase of selected plasma protein AGEs and DT in children with ASD and also decreased CL of arginine and CMA. These findings implicate a disturbance of metabolism of dicarbonyl precursors of AGEs and activation of dual 
oxidase (DUOX) in ASD. The initial evidence given herein suggests combination of plasma protein AGE and DT levels may provide a blood-based test for diagnosis of ASD. Decreased CL of arginine and CMA is proposed to be linked to amino acid transporter dysfunction in ASD, building on increasing evidence of neuronal amino acid availability as a driver in ASD development.

\section{Methods}

\section{Subject recruitment}

A total of 69 children were recruited. Of these, 38 had a diagnosis of ASD ( 29 males and 9 females) and 31 were classified as typically developing (TD) children (23 males and 8 females)-Fig. 2. The age of the two subject groups was not significantly different. Subject age was as follows: ASD group, 7.6 years \pm 2.0 years, range $5-12$ years and TD group, $8.6 \pm 2.0$ years, range $5-12$ years. All ASD subjects received a diagnosis of ASD by two child development experts at the Child Neurology and Psychiatry Unit of the Bellaria Hospital of Bologna (IRCCS Institute of Neurological Sciences), according to the Diagnostic and Statistical Manual of Mental Disorders V (DSM 5 [1] criteria, Autism Diagnostic Observation Schedule (ADOS) [10], Childhood Autism Rating Scale (CARS) [17] and characteristics of onset pattern of ASD defined according to Ozonoff et al. [18]. Developmental and cognitive levels were assessed by Psychoeducational Profile-3 (PEP-3) [19] and Leiter International Performance Scale-Revised (Leiter-R) [20]. For both ASD and TD subjects, exclusion criteria were presence of inflammatory or infective disease and taking antioxidant supplements at the time of study. No subject underwent any surgery intervention in the 4 months prior to blood and urine collection. None of the ASD subjects had active epilepsy at the time of blood and urine sampling. Subjects with ascertained medical and neurological comorbidity were excluded, through a medical work up including electroencephalography (recorded during awake and sleep), cerebral magnetic resonance imaging, standard clinical and neurological examination, neurometabolic, and genetic investigations (including comparative genomic hybridization array, molecular assay for Fragile $\mathrm{X}$ and MECP2). Subjects recruited for this

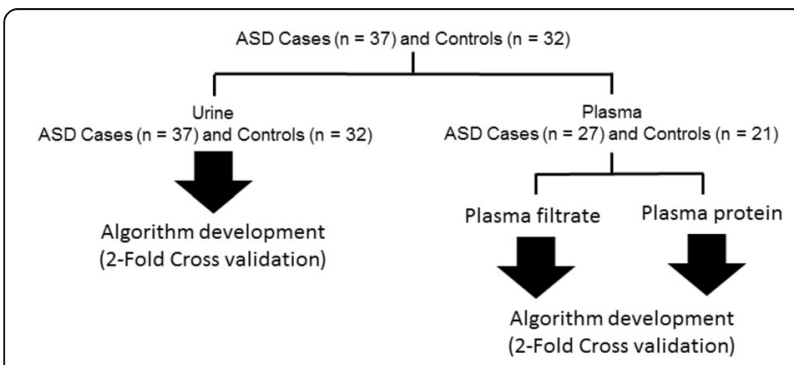

Fig. 2 Training and validation subject groups of diagnostic algorithms for detection of autistic spectrum disorder study were not taking any medication. TD children were recruited in the local community, with no sign of cognitive, learning, and psychiatric involvement. They were attending mainstream school and had not been subjected to stressful events. Dietary habits were assessed by a Food Questionnaire, built according to the guidelines issued by the Emilia-Romagna Health Authority. No ASD child was on a diet free of gluten or casein. Both patients and controls were on a typical Mediterranean diet, as defined by the prevalence of both simple and complex carbohydrates, use of olive oil, and plenty of fruit [21]. The consumption of vegetables was less than desirable in both patients and controls, although vegetable intake was more limited in ASD patients. Demographic and clinical features of ASD are summarized in Table 1 . All subjects were recruited at the Child Neurology and Psychiatry Unit of the Bellaria Hospital of Bologna, Bologna, Italy.

\section{Blood and urine sampling}

Blood was withdrawn in the morning from fasting children. Spot urine samples were the first ones in the morning. Blood samples were collected using ethylenediaminetetra-acetic acid (EDTA) as anticoagulant. Plasma and blood cells were separated immediately by centrifugation $(2000 g, 10 \mathrm{~min})$ and plasma samples stored at $-80{ }^{\circ} \mathrm{C}$ until analysis and transferred between collaborating laboratories on dry ice.

\section{Assay of markers of protein glycation, oxidation, and nitration}

The content of glycated, oxidized, and nitrated adduct residues in plasma protein was quantified in exhaustive enzymatic digests by stable isotopic dilution analysis liquid chromatography-tandem mass spectrometry (LC-MS/ MS), with correction for autohydrolysis of hydrolytic enzymes [22]. The concentrations of related glycated, oxidized, and nitrated amino acids related free adducts (glycated, oxidized, and nitrated amino acids) in plasma and urine were determined similarly in plasma and urine ultrafiltrate, respectively. Ultrafiltrate of plasma $(50 \mu \mathrm{L})$ was collected by microspin ultrafiltration (10 kDa cut-off) at $4{ }^{\circ} \mathrm{C}$. Retained protein was diluted with water to $500 \mu \mathrm{L}$ and washed by 4 cycles of concentration to $50 \mu \mathrm{L}$ and dilution to $500 \mu \mathrm{L}$ with water over the microspin ultrafilter at $4{ }^{\circ} \mathrm{C}$. The final washed protein $(100 \mu \mathrm{L})$ was delipidated and hydrolysed enzymatically as described [22, 23]. Ultrafiltrate of urine $(50 \mu \mathrm{L})$ was collected by microspin ultrafiltration (3 kDa cut-off) at $4{ }^{\circ} \mathrm{C}$.

Protein hydrolysate ( $25 \mu \mathrm{L}, 32 \mu \mathrm{g}$ equivalent) or ultrafiltrate $(5 \mu \mathrm{L})$ was mixed with stable isotopic standard analytes (amounts as given previously [24]) and analyzed by LC-MS/MS using an Acquity ${ }^{\mathrm{TM}}$ UPLC system with a Xevo-TQS tandem mass spectrometer (Waters, Manchester, UK). Samples are maintained at $4{ }^{\circ} \mathrm{C}$ in the 
Table 1 Demographic and clinical features of the autistic children group

\begin{tabular}{|c|c|c|c|c|c|c|c|c|c|c|c|c|c|c|}
\hline \multirow[t]{2}{*}{ No } & \multirow[t]{2}{*}{$\begin{array}{l}\text { Age } \\
\text { (years) }\end{array}$} & \multirow[t]{2}{*}{ Gender } & \multirow[t]{2}{*}{$\begin{array}{l}\text { ADOS } \\
\text { score }\end{array}$} & \multirow{2}{*}{$\begin{array}{l}\text { CARS } \\
\text { total } \\
\text { score }\end{array}$} & \multirow{2}{*}{$\begin{array}{l}\text { CARS activity } \\
\text { level item } \\
\text { score } \\
\text { (hyperactivity) }\end{array}$} & \multirow{2}{*}{$\begin{array}{l}\text { CARS body } \\
\text { use item } \\
\text { score } \\
\text { (stereotypes) }\end{array}$} & \multirow{2}{*}{$\begin{array}{l}\text { CARS } \\
\text { total } \\
\text { number } \\
\text { of items } \\
\text { with } \\
\text { score } \geq \\
3\end{array}$} & \multirow{2}{*}{$\begin{array}{l}\text { Autism } \\
\text { severity } \\
\text { level }\end{array}$} & \multirow{2}{*}{$\begin{array}{l}\text { Cognitive/ } \\
\text { developmental } \\
\text { impairment }\end{array}$} & \multirow{2}{*}{$\begin{array}{l}\text { Onset } \\
\text { pattern (1, } \\
\text { early; 2, } \\
\text { regressive; } \\
3 \text {, mixed) }\end{array}$} & \multicolumn{4}{|c|}{$\begin{array}{l}\text { Probability of autism } \neq \text { from } \\
\text { algorithm no. }\end{array}$} \\
\hline & & & & & & & & & & & 1 & 2 & 3 & 4 \\
\hline 1 & 6.0 & $\mathrm{~m}$ & 22 & 41.0 & 2.0 & 3.0 & 9 & Severe & Severe & 1 & 0.93 & 0.79 & 0.82 & 0.80 \\
\hline 2 & 5.6 & $\mathrm{~m}$ & 14 & 34.0 & 2.0 & 2.0 & 2 & Mild & Mild & 1 & 1.00 & 0.71 & 0.99 & 0.77 \\
\hline 3 & 5.5 & $\mathrm{~m}$ & 18 & 40.5 & 2.5 & 3.5 & 9 & Severe & Moderate & 1 & 1.00 & 0.86 & 1.00 & 0.29 \\
\hline 4 & 5.4 & $f$ & 17 & 31.5 & 2.0 & 2.0 & 1 & Mild & Mild & 3 & 0.88 & 0.69 & 0.55 & 0.27 \\
\hline 5 & 8.5 & $\mathrm{~m}$ & 22 & 36.5 & 2.0 & 2.5 & 6 & Mild & Mild & 3 & 0.98 & 0.64 & 1.00 & 0.88 \\
\hline 6 & 8.7 & $\mathrm{~m}$ & 19 & 44.5 & 3.0 & 3.0 & 11 & Severe & Moderate & 2 & 1.00 & 0.69 & 1.00 & 0.74 \\
\hline 7 & 6.8 & $\mathrm{~m}$ & 19 & 36.5 & 2.5 & 2.0 & 7 & Mild & Normal IQ & 1 & 1.00 & 0.63 & 1.00 & 0.91 \\
\hline 8 & 5.5 & $f$ & 15 & 41.5 & 2.5 & 2.0 & 9 & Severe & Borderline IQ & 1 & 0.73 & 0.77 & 0.72 & 0.92 \\
\hline 9 & 11.9 & $\mathrm{~m}$ & 22 & 44.5 & 2.5 & 3.0 & 11 & Severe & Severe & 2 & 0.20 & 0.91 & 0.34 & 0.45 \\
\hline 10 & 9.2 & $f$ & 15 & 47.5 & 3.5 & 3.0 & 13 & Severe & Moderate & 1 & 0.84 & 0.88 & 0.94 & 0.36 \\
\hline 11 & 12.0 & $\mathrm{~m}$ & 20 & 39.0 & 3.0 & 3.5 & 8 & Severe & Severe & 3 & 0.94 & 0.68 & 0.82 & 0.63 \\
\hline 12 & 6.2 & $\mathrm{~m}$ & 22 & 42.5 & 3.0 & 2.5 & 10 & Severe & Severe & 1 & 1.00 & 0.69 & 1.00 & 0.98 \\
\hline 13 & 6.7 & $\mathrm{~m}$ & 21 & 40.5 & 2.5 & 3.0 & 9 & Severe & Severe & 2 & 0.83 & 0.51 & 0.85 & 0.56 \\
\hline 14 & 6.6 & $\mathrm{~m}$ & 19 & 37.0 & 2.5 & 3.0 & 7 & Severe & Moderate & 1 & 0.83 & 0.63 & 0.74 & 0.97 \\
\hline 15 & 5.5 & $\mathrm{~m}$ & 22 & 40.5 & 3.0 & 3.0 & 9 & Severe & Moderate & 3 & 0.68 & 0.57 & 0.82 & 0.98 \\
\hline 16 & 5.7 & $\mathrm{~m}$ & 20 & 41.5 & 2.5 & 3.0 & 11 & severe & severe & 1 & 0.98 & 0.81 & 0.98 & 0.81 \\
\hline 17 & 7.8 & $\mathrm{~m}$ & 21 & 46.0 & 3.5 & 4.0 & 11 & Severe & Severe & 1 & 0.83 & 0.35 & 0.52 & 0.79 \\
\hline 18 & 5.7 & $f$ & 20 & 43.5 & 2.5 & 3.0 & 10 & Severe & Normal IQ & 3 & 0.85 & 0.39 & 0.58 & 0.68 \\
\hline 19 & 7.8 & $\mathrm{~m}$ & 20 & 48.5 & 3.0 & 4.0 & 12 & Severe & Severe & 2 & 0.95 & 0.58 & 0.93 & 0.57 \\
\hline 20 & 6.8 & $\mathrm{~m}$ & 19 & 42.0 & 3.0 & 3.0 & 9 & Severe & Moderate & 2 & 0.67 & 0.61 & 0.54 & 0.77 \\
\hline 21 & 9.6 & $\mathrm{~m}$ & 19 & 39.5 & 3.0 & 3.0 & 7 & Severe & Severe & 1 & 0.55 & 0.44 & 0.62 & 0.51 \\
\hline 22 & 6.2 & $\mathrm{~m}$ & 19 & 41.0 & 2.5 & 3.0 & 9 & Severe & Severe & 3 & 0.81 & 0.32 & 0.78 & 0.73 \\
\hline 23 & 8.3 & $\mathrm{~m}$ & 16 & 35.0 & 2.5 & 2.0 & 3 & Moderate & Moderate & 1 & 0.70 & 0.35 & 0.63 & 0.56 \\
\hline 24 & 7.1 & $\mathrm{~m}$ & 22 & 41.0 & 2.5 & 2.0 & 7 & Severe & Moderate & 1 & 0.83 & 1.00 & 0.99 & 1.00 \\
\hline 25 & 6.2 & $f$ & 17 & 38.0 & 2.0 & 2.5 & 7 & Severe & Severe & 1 & 0.28 & 0.82 & 0.15 & 0.79 \\
\hline 26 & 10.3 & $f$ & 21 & 33.5 & 2.0 & 2.0 & 4 & Moderate & Normal IQ & 3 & 0.89 & 0.55 & 0.82 & 0.86 \\
\hline 27 & 10.7 & $\mathrm{~m}$ & 19 & 39.0 & 2.0 & 2.5 & 7 & Moderate & Normal IQ & 1 & 0.89 & 0.60 & 0.97 & 0.52 \\
\hline 28 & 6.5 & $\mathrm{~m}$ & 17 & 39.0 & 3.0 & 2.5 & 6 & Moderate & Normal IQ & 3 & ND & ND & ND & 0.76 \\
\hline 29 & 8.0 & $\mathrm{~m}$ & 22 & 44.0 & 2.5 & 3.0 & 11 & Severe & Moderate & 1 & ND & ND & ND & 0.54 \\
\hline 30 & 7.0 & $\mathrm{~m}$ & 18 & 39.5 & 2.5 & 3.0 & 8 & Moderate & Normal IQ & 1 & ND & ND & ND & 0.96 \\
\hline 31 & 9.5 & $\mathrm{~m}$ & 21 & 47.0 & 3.0 & 3.5 & 13 & Severe & Severe & 1 & ND & ND & ND & 0.29 \\
\hline 32 & 8.6 & $\mathrm{~m}$ & 16 & 41.5 & 4.0 & 2.0 & 10 & Severe & Moderate & 3 & ND & ND & ND & 0.33 \\
\hline 33 & 10.9 & $\mathrm{~m}$ & 18 & 35.0 & 2.0 & 3.0 & 3 & Mild & Normal IQ & 1 & $N D$ & ND & ND & 0.28 \\
\hline 34 & 5.8 & f & 18 & 43.0 & 2.5 & 3.0 & 11 & Severe & Moderate & 2 & ND & ND & ND & 0.30 \\
\hline 35 & 5.3 & $f$ & 17 & 39.5 & 2.5 & 2.5 & 6 & Moderate & Normal IQ & 1 & ND & ND & ND & 0.62 \\
\hline 36 & 5.3 & $f$ & 17 & 41.0 & 2.5 & 2.5 & 7 & Severe & Normal IQ & 1 & ND & ND & ND & 0.77 \\
\hline 37 & 8.2 & $\mathrm{~m}$ & 20 & 41.0 & 2.0 & 3.5 & 9 & Severe & Moderate & 1 & ND & ND & ND & 0.58 \\
\hline 38 & 11.1 & $\mathrm{~m}$ & 13 & 34.0 & 2.0 & 1.5 & 2 & Mild & Normal IQ & 3 & ND & ND & $\mathrm{ND}$ & 0.87 \\
\hline
\end{tabular}

tOnset pattern was defined according to Ozonoff et al. [18]

¥Probability the subject has autism estimated from diagnostic algorithms derived from experimental biomarker data—see Table 7 
autosampler during batch analysis. The columns were $2.1 \times 50 \mathrm{~mm}$ and $2.1 \mathrm{~mm} \times 250 \mathrm{~mm}, 5 \mu \mathrm{m}$ particle size Hypercarb $^{\text {Tw }}$ (Thermo Scientific), in series with programmed switching, at $30{ }^{\circ} \mathrm{C}$. Chromatographic retention was necessary to resolve oxidized analytes from their amino acid precursors to avoid interference from partial oxidation of the latter in the electrospray ionization source of the mass spectrometric detector. Analytes were detected by electrospray positive ionization and mass spectrometry multiple reaction monitoring (MRM) mode where analyte detection response was specific for mass/charge ratio of the analyte molecular ion and major fragment ion generated by collision-induced dissociation in the mass spectrometer collision cell. The ionization source and desolvation gas temperatures were 120 and $350{ }^{\circ} \mathrm{C}$, respectively; cone gas and desolvation gas flow rates were 99 and $900 \mathrm{~L} / \mathrm{h}$; and the capillary voltage was $0.60 \mathrm{kV}$. Argon gas $(5.0 \times$ $10^{-3}$ mbar) was in the collision cell. For MRM detection, molecular ion and fragment ion masses and collision energies optimized to $\pm 0.1 \mathrm{Da}$ and $\pm 1 \mathrm{eV}$, respectively, were programmed [22]-Additional file 1: Table S1. Analytes determined were glycation adducts-FL, and AGEs, CML, $N_{\varepsilon}-(1$-carboxyethyl)lysine (CEL), pyrraline, CMA, G-H1, MG-H1, 3DG-H, MOLD and GSP; oxidation adducts-DT, NFK, AASA, GSA; nitration adduct, 3-NT; and all major amino acids. Oxidation, nitration, and glycation adduct residues are normalized to their amino acid residue precursors and given as millimoles/ mole amino acid modified, and related free adducts are given in nanomolar. Chemical structures and biochemical and clinical significance of these analytes have been described elsewhere $[9,25]$. Renal clearance (CL) of glycation, oxidation, and nitration free adducts and unmodified amino acids was deduced from plasma and spot urine collections: $\mathrm{CL}(\mu \mathrm{L} / \mathrm{mg}$ creatinine or $\mathrm{mL} / \mathrm{mg}$ creatinine $)=[\text { analyte }]_{\text {Urine }}(\mathrm{nmol} / \mathrm{mg}$ creatinine $) /[$ analyte $]_{\text {Plasma }}(\mathrm{pmol} / \mathrm{mL}$ or $\mathrm{nmol} / \mathrm{mL})$.

\section{Machine learning analysis}

The objective was to distinguish between children with ASD and healthy controls. In all cases, the diagnostic algorithms were trained on $50 \%$ of the cases and controls (training subset) before being used to predict the disease class for each sample in the remaining subjects (test set), twofold cross-validation. The outcome was to assign, for each test set sample, a set of probabilities corresponding to each of the ASD/control groups-the group assignment being that for which the probability is highest. Test data were held separate from algorithm training; algorithm settings were not adjusted once we began to analyze the test set data-thereby guarding against overfitting and hence providing a rigorous estimate of predictive performance. Four algorithm types were tested for performance: random forests, logistic regression, ensemble classifier, and support vector machines (SVMs) [26-28]. During the algorithm training, we used the complete panel of protein glycation, oxidation, and nitration adducts as features and developed algorithms for each analyte type: plasma protein adduct residues, plasma free adducts, and urinary free adducts. For the latter two, unmodified amino acids were also included as features. The aim during the training was to select the set of features that accomplishes the highest performance. The machine learning experiments initially explored using all metabolite features. Subsequent selection of a subset of discriminant biomarker features improved the algorithm performance. For the biomarker selection, we used a sequential feature selection approach. The biomarker feature selection and classifier selection were made on the basis of algorithm performance defined by classification accuracy, sensitivity, specificity, area under-the-curve of the receiver operating characteristic curve (AUROC), positive likelihood ratio, negative likelihood ratio, positive predictive value, negative predictive value, and $F$-measure. For each performance metric, the mean and $95 \% \mathrm{CI}$ was determined and reported. The algorithm training and testing was repeated 10 times, without altering the algorithm parameters, with $50 \%$ data split, to test for algorithm's robustness against any bias towards data split. We developed our computer programs using Statistics and Machine Learning Toolbox of MATLAB ${ }^{\circ}$ (MathWorks, Inc., Natick, USA), with a linear kernel SVM and sequential minimal optimization (SMO).

\section{Statistical analysis}

Data are presented as mean \pm SD for parametric distributions and median (lower-upper quartile) for nonparametric distributions. The test for normality of data distribution applied was the Kolmogorov-Smirnov test. Significance was evaluated by Student's $t$ test or by Mann-Whitney $U$ test for parametrically or nonparametrically distributed data, respectively. Bonferroni correction was made for analysis of multiple analytes without preconceived hypothesis. Correlation analysis was performed by Spearman's rho method with continuous variables. For clinical categorical variables with $\geq 6$ categories, Spearman correlation was performed-assuming approximation to a continuous variable [29]; for other categorical variables, significance of difference of biomarker data distributions between categories was assessed by oneway ANOVA for parametric data and Kruskal-Wallis $H$ test. Data were analyzed using SPSS, version 24.0.

For power analysis in the study design, we chose the level of the irreversible oxidative damage marker DT in plasma protein. In healthy human subjects, plasma protein DT was $0.0287 \pm 0.0027 \mathrm{mmol} / \mathrm{mol}$ tyr $(n=29)$ in 
previous studies [30]. We designed our study to detect a $50 \%$ increase in plasma protein DT at the $0.01 \%$ significance level, for which $\geq 18$ case and control samples were required. Post hoc analysis revealed an $88 \%$ increase with $P=0.00017$, after Bonferroni correction of 14,15 or 20 as appropriate with 27 cases and 21 controls, suggesting the study was adequately powered for this key target analyte.

\section{Results}

Children with autistic spectrum disorder recruited for this study

Thirty-eight children with ASD were recruited for this study. The distribution of severity of ASD in this subject group recruited was (number of cases) mild (6), moderate (6), and severe (26). The distribution of cognitive/developmental impairment was (number of cases) normal/ borderline IQ (11), mild (3), moderate (12), and severe (12). The distribution of onset pattern of ASD was (number of cases) early (22), regressive (6), and mixed (10). The ADOS score ranged from 13 to 22 and the CARS total score from 31.5 to 48.5 .

\section{Plasma protein glycation, oxidation, and nitration}

In plasma protein, protein content of AGEs-CML, MG$\mathrm{H} 1$ and CMA - were increased in children with ASD, with respect to healthy controls, whereas plasma protein content of AGE, 3DG-H, was decreased in children with ASD, with respect to healthy controls. Plasma protein content of the oxidative damage adduct, DT, was increased in children with ASD, with respect to healthy controls. Only changes in CML, CMA, and DT remained significant after Bonferroni correction for measurement of multiple analytes (Table 2). In correlation analysis, highly significant positive correlations $(P<0.01$, Spearman) were of CML with DT, G-H1 with MG-H1 and DT, MG-H1 with CMA, CMA with DT, and AASA with GSA-Additional file 1: Table S2. No correlation or association of glycation, oxidation, and nitration adduct residues was found with demographic and clinical features. There was no significant difference of these variables between subject groups of different genders with and without ASD.

\section{Plasma glycated, oxidized, and nitrated amino acids and amino acid metabolome}

For glycated, oxidized, and nitrated amino acid concentration in plasma, FL, G-H1, and NFK were decreased whereas CMA, AASA, and GSA were increased in children with ASD, with respect to healthy controls. Only increase in CMA remained significant after Bonferroni correction (Table 3). In correlation analysis, highly significant positive correlations were of pyrraline with MG$\mathrm{H} 1$ and 3DG-H, FL with CML, G-H1 and MG-H1, CEL with MG-H1 and CMA, MG-H1 with 3DG-H, and CMA with AASA. There were highly significant negative correlations of pyrraline with NFK, CMA with MOLD, and MOLD with AASA-Additional file 1: Table S3.

For the conventional amino acid metabolome, there were increases in arg, gln, glu, and thr and decrease in trp in children with ASD, with respect to healthy controls. None of these changes remained significant after Bonferroni correction (Table 4). There were many highly significant positive correlations between plasma amino acid concentrations-Additional file 1: Table S4. No correlation or association of glycation, oxidation, and nitration free adducts and amino acids

Table 2 Glycation, oxidation, and nitration adduct residue content of plasma protein

\begin{tabular}{llll}
\hline Glycation markers & Healthy controls & ASD & $P$ value \\
\hline FL (mmol/mol lys) & $1.27 \pm 0.39$ & $1.41 \pm 0.53$ & NS \\
CML (mmol/mol lys) & $0.158 \pm 0.026$ & $0.190 \pm 0.038$ & $0.0018^{*}$ \\
CEL (mmol/mol lys) & $0.117 \pm 0.044$ & $0.092 \pm 0.054$ & $\mathrm{NS}$ \\
G-H1 (mmol/mol arg) & $0.012 \pm 0.005$ & $0.016 \pm 0.011$ & $\mathrm{NS}$ \\
MG-H1 (mmol/mol arg) & $0.473 \pm 0.074$ & $0.535 \pm 0.100$ & 0.021 \\
3DG-H (mmol/mol arg) & $0.165 \pm 0.037$ & $0.138 \pm 0.027$ & 0.0052 \\
CMA (mmol/mol arg) & $0.054(0.043-0.067)$ & $0.077(0.066-0.101)$ & $0.000082^{* *}$ \\
MOLD (mmol/mol lys) & $0.027 \pm 0.011$ & $0.025 \pm 0.016$ & $\mathrm{NS}$ \\
GSP (mmol/mol lys) & $0.514 \pm 0.111$ & $0.571 \pm 0.206$ & $\mathrm{NS}$ \\
DT (mmol/mol tyr) & $0.025(0.019-0.031)$ & $0.047(0.035-0.094)$ & $0.000012^{* * *}$ \\
NFK (mmol/mol trp) & $15.6 \pm 1.7$ & $15.0 \pm 1.5$ & $\mathrm{NS}$ \\
AASA (mmol/mol lys) & $0.154 \pm 0.048$ & $0.152 \pm 0.081$ & $\mathrm{NS}$ \\
GSA (mmol/mol arg) & $0.639 \pm 0.327$ & $0.713 \pm 0.350$ & $\mathrm{NS}$ \\
3-NT (mmol/mol tyr) & $0.0056(0.0045-0.0069)$ & $0.0053(0.0045-0.0064)$ & $\mathrm{NS}$ \\
\hline
\end{tabular}

Data are median (lower-upper quartile); healthy controls, $n=21$, and ASD, $n=27$. Significance (Mann-Whitney $U$ )

${ }^{*} P<0.05,{ }^{*} P<0.01$, and ${ }^{* * *} P<0.001$ after Bonferroni correction of 14 applied 
Table 3 Plasma and urinary glycation, oxidation, and nitration free adduct in plasma filtrate

\begin{tabular}{|c|c|c|c|c|c|c|}
\hline \multirow{2}{*}{$\begin{array}{l}\text { Amino } \\
\text { acid }\end{array}$} & \multicolumn{2}{|l|}{ Plasma (nM) } & \multirow[b]{2}{*}{$P$ value } & \multicolumn{3}{|c|}{ Urine (nmol/mg creatinine) } \\
\hline & Healthy controls & ASD & & Healthy controls & ASD & $P$ value \\
\hline $\mathrm{FL}$ & 1489 (987-1863) & $751(361-1.570)$ & 0.047 & $56.7(33.8-128.7)$ & $90.8(42.4-167.9)$ & \\
\hline$C M L$ & $807(587-1051)$ & $853(219-1222)$ & & $26.2(19.7-34.7)$ & $33.1(26.6-42.6)$ & 0.016 \\
\hline CEL & $402(298-477)$ & $420(310-599)$ & & $0.435(0.202-0.848)$ & $0.472(0.180-0.940)$ & \\
\hline $\mathrm{G}-\mathrm{H} 1$ & $0.819(0.553-1.26)$ & $0.527(0.366-0.959)$ & 0.037 & $1.88(1.11-3.04)$ & $2.57(1.53-3.75)$ & 0.024 \\
\hline MG-H1 & $271(176-475)$ & $335(213-500)$ & & $18.6(8.00-27.4)$ & $24.5(9.14-37.6)$ & \\
\hline 3DG-H & $413(303-637)$ & $360(280-434)$ & & $2.06(0.587-4.38)$ & $2.92(1.09-6.26)$ & \\
\hline CMA & $9.18(6.67-12.5)$ & $17.7(13.2-24.8)$ & $0.00052^{* *}$ & $1.46(0.636-1.97)$ & $1.78(1.14-2.91)$ & 0.037 \\
\hline GSP & $12.8(7.4-17.1)$ & $12.9(9.3-22.0)$ & & $1.58(1.15-1.98)$ & $1.53(1.20-1.98)$ & \\
\hline MOLD & $1.79(0.800-3.42)$ & $1.10(0.503-0.2 .21)$ & & $0.025(0.013-0.050)$ & $0.040(0.017-0.068)$ & 0.027 \\
\hline Pyrraline & $22.0(12.2-30.4)$ & $24.2(19.4-40.6)$ & & $20.6(14.9-44.2)$ & $34.2(22.7-72.5)$ & 0.047 \\
\hline DT & $0.501(0.286-0.771)$ & $0.676(0.500-0.847)$ & & $0.070(0.058-0.085)$ & $0.086(0.075-0.109)$ & $0.0022^{*}$ \\
\hline NFK & $15.2(12.5-18.1)$ & $11.3(6.23-14.3)$ & 0.030 & $0.117(0.084-0.231)$ & $0.179(0.107-0.238)$ & 0.037 \\
\hline AASA & $19.7(16.9-29.1)$ & $30.6(21.1-46.4)$ & 0.0063 & $1.08(0.805-2.76)$ & $1.80(1.13-2.89)$ & 0.040 \\
\hline GSA & $73.9(53.2-129)$ & $109(80.1-203)$ & 0.039 & $17.3(13.2-22.7)$ & $34.5(12.7-48.0)$ & $0.0018^{*}$ \\
\hline 3-NT & $1.10(0.90-1.26)$ & $1.17(0.79-1.58)$ & & $0.0044(0.001-0.010)$ & $0.0077(0.003-0.014)$ & \\
\hline
\end{tabular}

Data are median (lower - upper quartile); healthy controls, $n=21-31$, and ASD, $n=27-38$. Significance (Mann-Whitney $U$ )

${ }^{*} P<0.05$ after Bonferroni correction of 15 applied

Table 4 Plasma and urinary amino acid metabolome

\begin{tabular}{|c|c|c|c|c|c|c|}
\hline \multirow{2}{*}{$\begin{array}{l}\text { Amino } \\
\text { acid }\end{array}$} & \multicolumn{2}{|l|}{ Plasma $(\mu \mathrm{M})$} & \multirow[b]{2}{*}{$P$ value } & \multicolumn{3}{|c|}{ Urine (nmol/mg creatinine) } \\
\hline & Healthy controls & ASD & & Healthy controls & ASD & $P$ value \\
\hline$\overline{\text { Ala }}$ & $294 \pm 71.5$ & $330 \pm 98.3$ & & $301(224-432)$ & $392(305-533)$ & 0.030 \\
\hline Arg & $39.4 \pm 10.3$ & $48.4 \pm 16.6$ & 0.016 & $52.1 \pm 17.1$ & $64.0 \pm 18.0$ & 0.014 \\
\hline Asn & $33.2 \pm 4.57$ & $34.3 \pm 10.6$ & & $92.4(72.1-132)$ & $169(123-236)$ & $0.0012^{*}$ \\
\hline Asp & $35.5 \pm 7.37$ & $37.0 \pm 10.0$ & & $142(112-179)$ & $160(117-241)$ & \\
\hline Cys (total) & $41.7 \pm 10.4$ & $46.1 \pm 15.0$ & & $25.3(20.4-35.9)$ & $28.3(21.1-43.3)$ & \\
\hline Gln & $463 \pm 38.6$ & $496 \pm 61.2$ & 0.024 & $529(452-704)$ & $741(609-876)$ & 0.0048 \\
\hline Glu & $1672 \pm 324$ & $1999 \pm 619$ & 0.034 & $373(254-495)$ & $475(367-690)$ & 0.010 \\
\hline Gly & $272(187-1061)$ & $241(121-515)$ & & $1.12(1.19-2.78)$ & $2.58(1.84-3.45)$ & 0.019 \\
\hline His & $68.0 \pm 8.51$ & $72.8 \pm 9.96$ & & $2.19 \pm 0.88$ & $2.90 \pm 1.21$ & 0.027 \\
\hline lle & $50.7 \pm 15.3$ & $51.6 \pm 12.4$ & & $13.0 \pm 4.37$ & $18.1 \pm 6.50$ & 0.0059 \\
\hline Leu & $126 \pm 34.4$ & $132 \pm 25.6$ & & $43.1 \pm 13.6$ & $52.0 \pm 13.5$ & 0.028 \\
\hline Lys & $132 \pm 20.3$ & $146 \pm 36.7$ & & $136(83.3-264)$ & $171(117-352)$ & \\
\hline Met & $23.1 \pm 6.41$ & $26.2 \pm 5.84$ & & $17.9 \pm 7.98$ & $23.1 \pm 7.20$ & 0.0037 \\
\hline Phe & $68.9 \pm 11.3$ & $68.8 \pm 16.8$ & & $101 \pm 38.9$ & $110 \pm 32.9$ & \\
\hline Pro & $195 \pm 65.4$ & $223 \pm 94.7$ & & $14.5 \pm 6.21$ & $20.7 \pm 5.37$ & $0.00073^{* *}$ \\
\hline Ser & $128 \pm 23.5$ & $132 \pm 18.7$ & & $461(413-621)$ & 677 (519-910) & $0.0021^{*}$ \\
\hline Thr & $116 \pm 36.0$ & $141 \pm 46.8$ & 0.041 & $216(170-265)$ & $283(221-405)$ & 0.0039 \\
\hline Trp & $5.22 \pm 1.26$ & $3.92 \pm 2.40$ & 0.0055 & $114 \pm 73.6$ & $164 \pm 48.6$ & 0.0043 \\
\hline Tyr & $84.4 \pm 21.3$ & $87.9 \pm 26.8$ & & $204(133-255)$ & $240(173-317)$ & \\
\hline Val & $125 \pm 31.3$ & $120 \pm 26.0$ & & $25.6 \pm 9.52$ & $34.8 \pm 10.9$ & $0.00073^{* *}$ \\
\hline
\end{tabular}

Data are Mean \pm SD or median (lower-upper quartile); healthy controls, $n=21$, and ASD, $n=27$. Significance: $t$ test for parametric data and Mann-Whitney $U$ for non-parametric data 
was found with demographic and clinical features. There was no significant difference of these variables between genders.

\section{Urinary glycated, oxidized, and nitrated amino acids and} amino acid metabolome and renal clearance

For the urinary flux of glycated, oxidized, and nitrated amino acids, children with ASD showed increased urinary excretion of CML, G-H1, CMA, MOLD, pyrraline, DT, NFK, AASA, and GSA. Only urinary excretions of DT and GSA remained significant after Bonferroni correction (Table 3). For the urinary flux of unmodified amino acids, children with ASD showed increased urinary excretion of all amino acids except asp, cys, lys, phe, and tyr. Only increases in urinary excretion of asn, pro, ser, and val remained significant after Bonferroni correction (Table 4). There were several highly significant positive correlations between urinary excretions of glycation, oxidation, and nitration adducts and amino acids-see Additional file 1: Table S5 and Table S6.

Renal clearance of CMA, GSP, DT, arg, glu, leu, phe, and thr were decreased and renal clearance of NFK and trp were increased in children with ASD, with respect to healthy controls. Only decreases in renal clearance of arg and CMA remained significant after Bonferroni correction: $\mathrm{CL}_{\text {arg }}$ decreased $32 \%$ and $\mathrm{CL}_{\mathrm{CMA}}$ decreased $50 \%$ in children with ASD, compared to healthy control; $P<$ 0.001 (Tables 5 and 6). No correlation or association of these glycation, oxidation, and nitration free adduct and amino acid variables was found with demographic and clinical features. There was no significant difference of these variables between genders.

Changes of glycation, oxidation, and nitration adducts and amino acid metabolome in plasma and urine are summarized in heat maps (Fig. 3a, b). Data distributions of biomarker with significantly different change in the ASD study group after Bonferroni correction are given in Fig. 4.

\section{Development of diagnostic algorithms for ASD}

To explore diagnostic utility of protein glycation, oxidation, and nitration measurements for ASD, we analyzed plasma and urinary amino acid analyte data by a machine learning approach. SVMs was the best-performing method out of the four algorithms that were investigated. Algorithm optimized from twofold cross-validation were as below.

(i) Algorithm-1, developed from plasma protein glycation, oxidation, and nitration adduct residue analytes.

It has the following features: CML, 3DG-H, CMA, and DT. Classification accuracy was $88 \%$, sensitivity $92 \%$, specificity 84\%, and AUROC 0.94. A random outcome is 0.50 .
Table 5 Renal clearance of glycation, oxidation, and nitration free adducts

\begin{tabular}{llll}
\hline \multirow{2}{*}{$\begin{array}{l}\text { Amino } \\
\text { acid }\end{array}$} & \multicolumn{2}{l}{ Renal clearance $(\mu \mathrm{L} / \mathrm{mg}$ creatinine $)$} & \\
\cline { 2 - 3 } & Healthy controls & ASD & \\
\hline FL $^{\#}$ & $0.696(0.375-1.16)$ & $0.866(0.384-2.31)$ & \\
CML & $0.297(0.249-0.387)$ & $0.259(0.171-0.782)$ & \\
CEL & $0.0068(0.003-0.019)$ & $0.0042(0.002-0.011)$ & \\
G-H1 & $21.2(13.1-34.7)$ & $23.9(15.0-57.7)$ & \\
MG-H1 \# & $0.718(0.496-1.04)$ & $0.628(0.363-0.912)$ & \\
3DG-H & $0.067(0.033-0.163)$ & $0.087(0.042-0.131)$ & \\
CMA & $1.57(0.997-2.08)$ & $0.791(0.465-1.36)$ & $0.0011^{*}$ \\
GSP & $0.121(0.083-0.274)$ & $0.112(0.067-0.195)$ & \\
MOLD & $0.214(0.075-0.487)$ & $0.269(0.153-0.656)$ & \\
Pyrraline & $0.81(0.58-1.17)$ & $1.07(0.64-1.96)$ & \\
DT & $0.119(0.657-2.02)$ & $0.747(0.545-0.107)$ & 0.0025 \\
NFK & $0.062(0.038-0.109)$ & $0.096(0.049-0.139)$ & 0.030 \\
GSA & $29.9(11.1-45.8)$ & $17.8(1.96-26.1)$ & \\
3-NT & $0.068(0.034-0.100)$ & $0.042(0.036-0.129)$ & \\
\hline
\end{tabular}

Data are mean \pm SD or median (lower-upper quartile); healthy controls, $n=21$ and ASD, $n=27$. Significance: t-test for parametric data and Mann-Whitney $U$ for non-parametric data

${ }^{*} P<0.05$, after Bonferroni correction of 14 applied

${ }^{\#} \mathrm{~mL} / \mathrm{mg}$ creatinine

(ii)Algorithm-2, developed from plasma glycated, oxidized, and nitrated amino acids and conventional amino acid metabolome.

It has the following features: CML and CMA. Classification accuracy was $75 \%$, sensitivity $81 \%$, and specificity $67 \%$ and AUROC 0.80.

(iii) Algorithm-3, developed from plasma protein glycation, oxidation, and nitration adduct residues and plasma glycated, oxidized, and nitrated amino acids and conventional amino acid metabolome combined.

It has the following features: plasma protein CML, 3DG-H, CMA and DT residues, and plasma G-H1 and GSA free adducts. Classification accuracy was 89\%, sensitivity $90 \%$, specificity $87 \%$, and AUROC 0.95 .

(iv)Algorithm-4, developed from urinary glycated, oxidized, and nitrated amino acids.

It has the following features: GSA and pyrraline free adducts. Classification accuracy was $77 \%$, sensitivity 77\%, specificity 76\%, and AUROC 0.79 (Fig. 5, Table 7, and Additional file 1: Table S7).

The diagnostic algorithms were used to deduce the probability of having ASD for each patient diagnosed with ASD by clinical symptoms (Table 1 ). The association and 
Table 6 Renal clearance of amino acids

\begin{tabular}{|c|c|c|c|}
\hline \multirow{2}{*}{$\begin{array}{l}\text { Amino } \\
\text { acid }\end{array}$} & \multicolumn{2}{|c|}{ Renal clearance (mL/mg creatinine) } & \multirow[b]{2}{*}{$P$ value } \\
\hline & Healthy controls & ASD & \\
\hline Ala & $1.03(0.746-1.712)$ & $1.27(0.890-1.65)$ & \\
\hline Arg & $0.011(0.009-0.015)$ & $0.008(0.006-0.010)$ & $0.0019^{*}$ \\
\hline Asn & $2.80(2.22-4.76)$ & $4.30(3.05-7.14)$ & 0.0055 \\
\hline Asp & $3.81(3.04-4.96)$ & $4.73(2.92-7.82)$ & \\
\hline Cys (total) & $0.646(0.518-0.812)$ & $0.629(0.452-1.133)$ & \\
\hline$G \ln$ & $1.18(0.913-1.53)$ & $1.54(1.14-1.96)$ & 0.025 \\
\hline Glu & $0.210(0.158-0.304)$ & $0.243(0.179-0.357$ & 0.049 \\
\hline Gly & $0.0050(0.002-0.009)$ & $0.0067(0.004-0.029)$ & 0.018 \\
\hline His & $0.029(0.024-0.040)$ & $0.040(0.027-0.053)$ & \\
\hline lle & $0.262(0.192-0.347)$ & $0.354(0.256-0.441)$ & 0.0116 \\
\hline Leu & $0.358 \pm 0.135$ & $0.402 \pm 0.105$ & \\
\hline Lys & $0.011(0.005-0.018)$ & $0.0071(0.005-0.011)$ & \\
\hline Met & $0.0066 \pm 0.0015$ & $0.0056 \pm 0.0023$ & \\
\hline Phe & $1.32(0.959-2.02)$ & $1.65(1.33-1.95)$ & \\
\hline Pro & $0.077 \pm 0.031$ & $0.104 \pm 0.039$ & 0.0138 \\
\hline Ser & $3.66(2.95-4.79)$ & $5.22(3.99-6.78)$ & 0.0081 \\
\hline Thr & $2.023 \pm 0.765$ & $2.44 \pm 1.05$ & \\
\hline Trp & $0.209(0.155-0.242)$ & $0.287(0.166-0.497)$ & 0.010 \\
\hline Tyr & $0.0209(0.016-0.025)$ & $0.015(0.012-0.025)$ & \\
\hline Val & $0.0017(0.0014-0.0022)$ & $0.0016(0.0013-0.0026)$ & \\
\hline
\end{tabular}

Data are mean \pm SD or median (lower-upper quartile); healthy controls, $n=21$, and ASD, $n=27$. Significance: $t$ test for parametric data and Mann-Whitney $U$ for non-parametric data

${ }^{*} P<0.05$, after Bonferroni correction of 20 applied correlation of these probabilities with clinical features was explored. No significant association or correlation of these probabilities with clinical features (age, ADOS, total CARS, CARS hyperactivity and CARS body use scores, autism severity, cognitive/developmental impairment, and ASD onset pattern) was found.

\section{Discussion}

In this study, we identified changes in plasma protein AGE and oxidation adducts, increased CML, CMA, and DT and decreased 3DG-H in ASD. Combined in an algorithm, these features provided diagnostic performance improved over that previously achieved in transcriptomic, proteomic, and metabolomic studies [5-7] - with AUROC 0.94 and classification efficiency $88 \%$. This was slightly improved by combination with plasma G-H1 and GSA free adducts, with AUROC 0.95 and classification efficiency $89 \%$. This novel biomarker approach focused to protein damage or proteotoxic stress may lead to biochemicalbased diagnosis of ASD and suggests that protein AGE and oxidation may be linked to ASD pathogenesis.

Change in AGE and oxidation adduct content of plasma proteins relates to the rate of protein modification in the plasma compartment and, to a lesser extent, to modifications of plasma proteins in interstitial fluid. The major plasma protein albumin makes repeated cycles from plasma to interstitial fluid and lymph before degradation [31]. CML residues in plasma protein are mainly produced by the oxidative degradation of FL with a usually minor contribution from glycation by glyoxal. CML is also considered to be a marker of oxidative damage [32]. CMA is

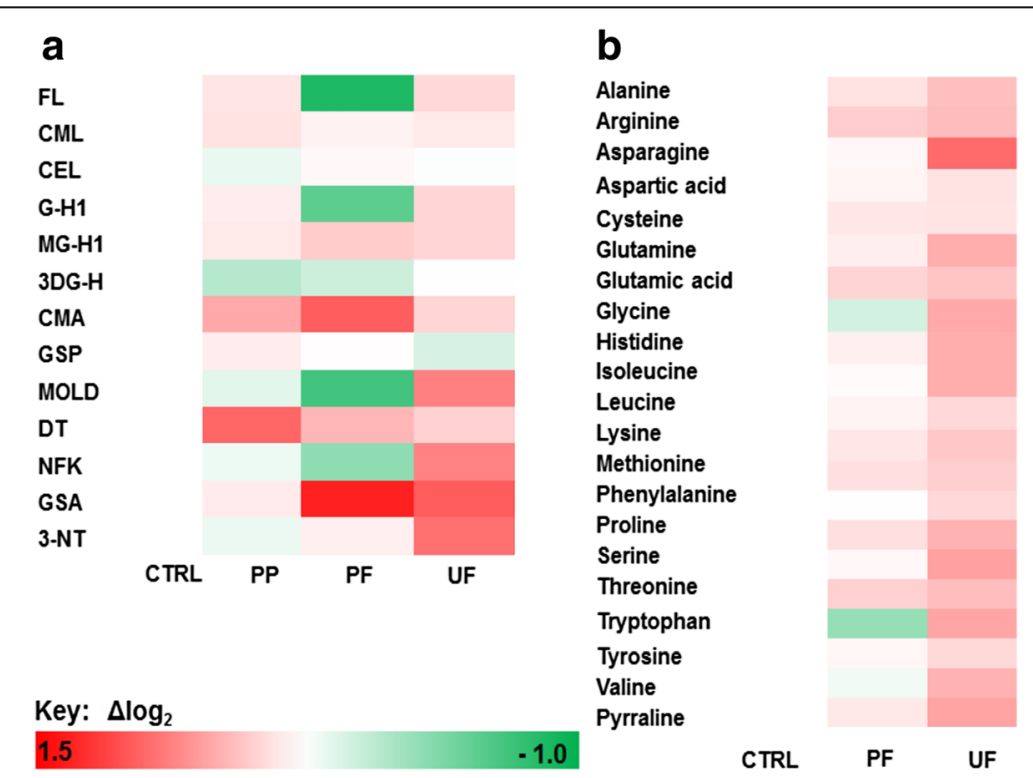

Fig. 3 Heat map of changes in glycated, oxidized, and nitrated proteins and amino acids in plasma and urine of subjects with autistic spectrum disorder. a Trace level protein glycation, oxidation, and nitration adducts. b Amino acid metabolome. Key: CTRL control, PP plasma protein (adduct residues), PF plasma filtrate (free adducts), and UF urine filtrate (free adducts). Data are given in Tables 2, 3, 4, and 5 

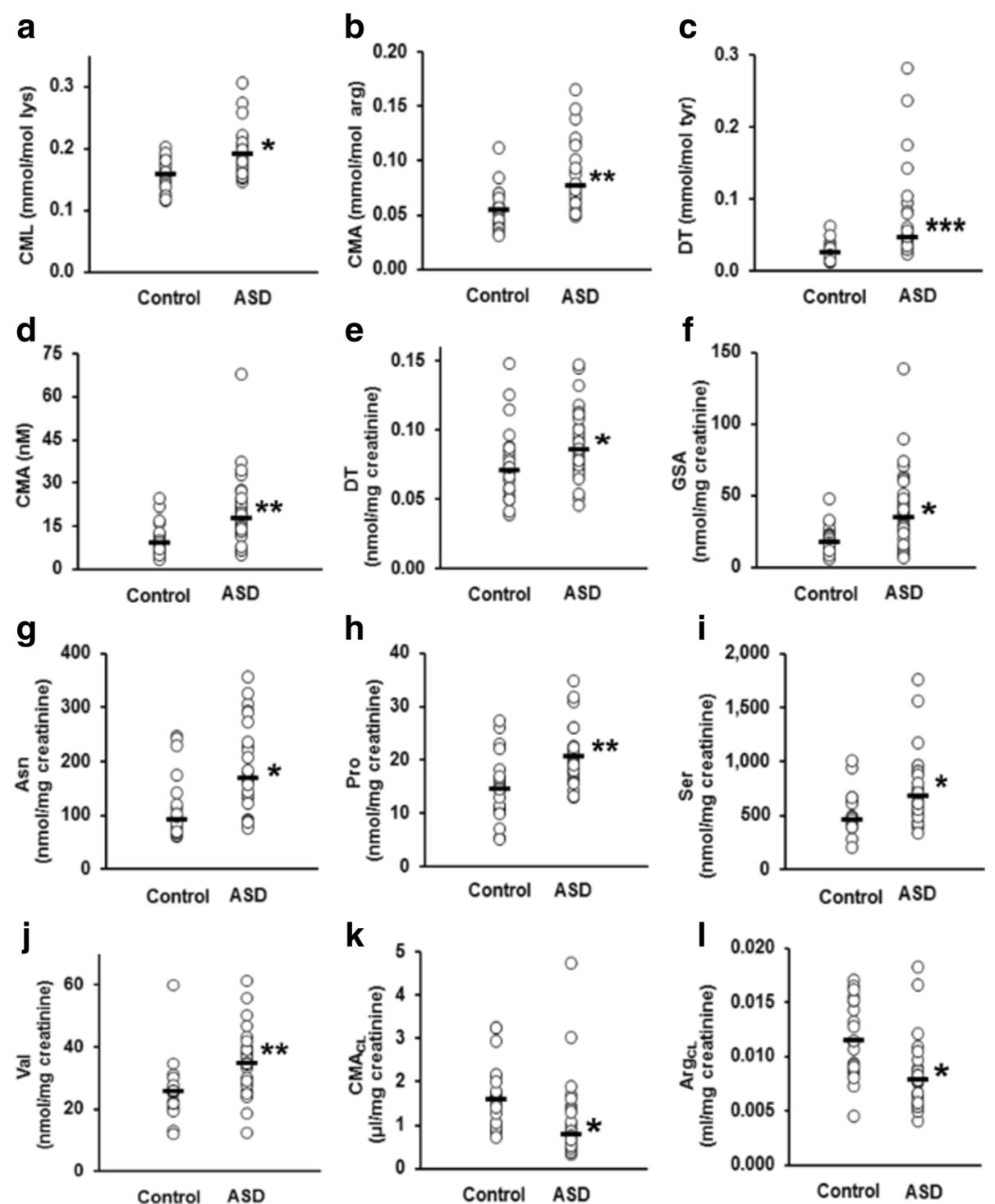

Fig. 4 Scatter plots for protein damage biomarker variables changed in children with ASD. Protein adduct residues: a CML, b CMA, and c DT. Plasma free adduct: $\mathbf{d}$ CMA. Urine free adduct and amino acids: e DT, f GSA, g Asn, h Pro, i Ser, and $\mathbf{j}$ Val. Renal clearance: $\mathbf{k}$ CMA and I Arg (an outlier point, 0.0565, was excluded from the ASD data). Significance: One asterisk, two asterisks, and three asterisks indicate $P<0.05, P<0.01$, and $P<0.001$, respectively

produced exclusively by the glycation of proteins by glyoxal [9]. Increased formation of glyoxal, mainly sourced from lipid peroxidation, in ASD may explain increases in plasma protein CML and CMA (Fig. 6a). Markers of lipid peroxidation, plasma and red blood cell malondialdehyde, urinary 8-isoprostane-F2a, and hexanoyl-lysine adduct were elevated in ASD [33-35].

DT residue content of plasma proteins was increased in subjects with ASD whereas other oxidative damage markers, NFK, AASA, and GSA, were not. DT residue formation occurs by reaction of tyrosine residues in proteins with ROS and DUOX [36]. The selective increase in DT may suggest a role of increased DUOX activity in subjects with ASD. DUOX expression is increased through activating transcription factor 2 in inflammatory signaling [37]. DUOX has an important role in gut mucosal immunity, host-microbe homeostasis, and signaling for neutrophil recruitment into allergic airways [38, 39]. Gut microbiota may be influential in the development of the behavioral phenotype in ASD children [40] (Fig. 6a).

Decrease of 3DG-H content of plasma protein in subjects with ASD likely reflects decreased concentration of plasma 3-DG. 3-DG is formed by degradation of fructosamine-3phosphate in the repair of early glycated proteins and degradation of fructose-3-phosphate formed by fructosamine3 -phosphokinase $[41,42]$ and the slow, non-enzymatic 

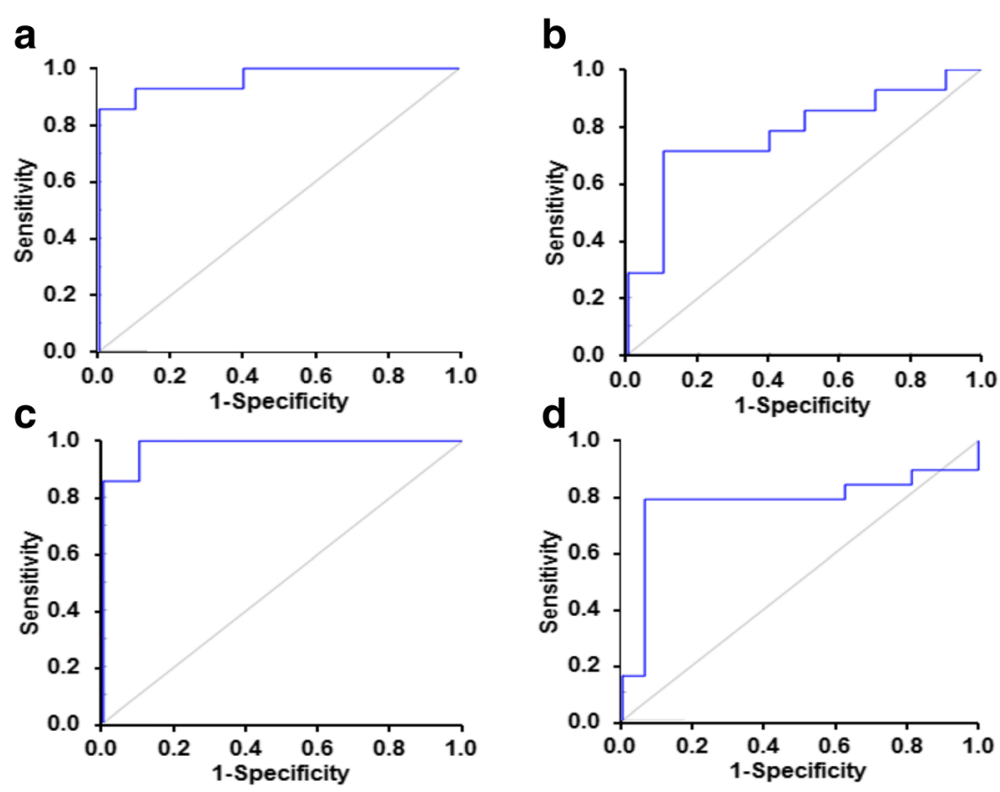

Fig. 5 Receiver operating characteristic plots of diagnostic algorithms for detection of autistic spectrum disorder by protein glycation and oxidation adducts. a Algorithm-1, plasma protein adduct residues. $A \cup R O C=0.96$. b Algorithm-2, plasma free adducts. AUROC $=0.78$. $\mathbf{c}$ Algorithm-3, plasma protein adduct residues and free adducts. AUROC $=0.99$. $\mathbf{d}$ Algorithm-4, urine free adducts. $A \cup R O C=0.78$. ROC plots are representative results from one run of the classification experiment. A random outcome is $A \cup R O C=0.50$

oxidative degradation of glucose and proteins glycated by glucose [43]. It is metabolized to 3-deoxyfructose by aldoketo reductases $1 \mathrm{~A} 4,1 \mathrm{~B} 1$, and $1 \mathrm{~B} 3$ which together constitute 3-DG reductase activity [44]. Since FL residue content of subjects with ASD was unchanged, with respect to healthy controls, there is unlikely to be decreased activity of fructosamine-3-phosphokinase in ASD. Rather, increased 3-DG reductase activity may explain decrease in plasma protein 3DG-H residue content in ASD (Fig. 6a).
Combination of markers of oxidative metabolism, DNA oxidation, and methylation in multivariate statistical models was recently found to distinguish between children with ASD and healthy controls [12]. Herein, oxidative damage markers, plasma protein CML and DT and plasma GSA free adduct, emerged as features of diagnostic algorithms for ASD. Measurement of multiple chemically defined markers of protein oxidative damage in plasma and urine compartments in subjects with and

Table 7 Diagnostic algorithms developed for autistic spectrum disorder from plasma and urinary analytes

\begin{tabular}{|c|c|c|c|c|}
\hline Algorithm no & 1 & 2 & 3 & 4 \\
\hline $\begin{array}{l}\text { Compartment and } \\
\text { analyte }\end{array}$ & $\begin{array}{l}\text { Plasma protein adduct } \\
\text { residues }\end{array}$ & $\begin{array}{l}\text { Plasma amino } \\
\text { acids }\end{array}$ & Plasma protein adduct residues and amino acids & Urinary amino acids \\
\hline Features & $\begin{array}{l}\text { CML, 3DG-H, CMA, and } \\
\text { DT }\end{array}$ & CML and CMA & $\begin{array}{l}\mathrm{CML}, 3 \mathrm{DG}-\mathrm{H}, \mathrm{CMA} \text {, and DT residues with } \mathrm{G}-\mathrm{H} 1 \text { and } \\
\text { GSA free adducts }\end{array}$ & $\begin{array}{l}\text { GSA and pyrraline free } \\
\text { adducts }\end{array}$ \\
\hline Accuracy (\%) & $88.3(85.5-91.2)$ & $74.8(71.7-77.9)$ & $89.0(87.0-91.0)$ & $76.8(74.6-79.0)$ \\
\hline Sensitivity (\%) & $91.9(89.1-94.6)$ & $80.5(75.1-86.0)$ & $90.4(87.7-93.1)$ & $77.1(73.4-80.8)$ \\
\hline Specificity (\%) & $83.9(79.3-88.4)$ & $67.1(58.9-75.4)$ & $87.3(84.1-90.5)$ & $76.4(72.0-80.8)$ \\
\hline AUROC & $0.94(0.91-0.96)$ & $0.80(0.77-0.83)$ & $0.95(0.94-0.96)$ & $0.79(0.76-0.81)$ \\
\hline Positive likelihood ratio & $5.69(4.49-6.89)$ & $2.85(2.16-3.55)$ & $7.23(6.09-8.38)$ & $4.16(2.88-5.44)$ \\
\hline $\begin{array}{l}\text { Negative likelihood } \\
\text { ratio }\end{array}$ & $0.10(0.07-0.13)$ & $0.28(0.21-0.35)$ & $0.11(0.08-0.14)$ & $0.30(0.25-0.34)$ \\
\hline $\begin{array}{l}\text { Positive predictive } \\
\text { value }(\%)\end{array}$ & $88.2(85.0-91.4)$ & $77.1(72.9-81.4)$ & $90.2(87.9-92.5)$ & $80.6(77.6-83.5)$ \\
\hline $\begin{array}{l}\text { Negative predictive } \\
\text { value }(\%)\end{array}$ & $89.1(85.5-92.6)$ & $75.0(70.6-79.4)$ & $88.0(85.1-91.0)$ & $73.7(71.0-76.5)$ \\
\hline F score & $0.90(0.87-0.92)$ & $0.78(0.75-0.81)$ & $0.90(0.88-0.92)$ & $0.78(0.76-0.81)$ \\
\hline
\end{tabular}

Algorithm outcomes for twofold cross-validation (10 randomized repeat trials for robustness) using SVMs (95\% Cl given in brackets) 


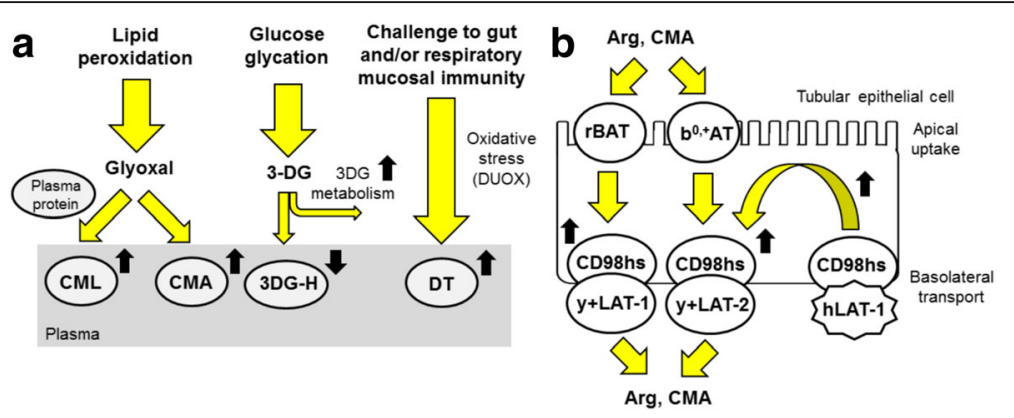

Fig. 6 Schematic explanation for changes found in protein damage and amino acids in ASD. a Proposed mechanism for observed changes found in plasma protein glycation and oxidation adducts. b Transport of arg and CMA across the renal tubular epithelium and proposed mechanism for increased renal CL (increased arg and CMA reuptake). Key: yellow-filled arrows show processes; black-filled arrows show changes observed (a) and changes expected (b) in ASD

without ASD has provided evidence of changes specific to oxidative damage marker type and sample compartment that likely contributed to algorithm development for ASD with improved diagnostic performance.

For unmodified amino acids, we found no changes after correction for multiple measurements in plasma but there were significant increases in urinary excretion of asn, pro, ser, and val. This may relate to impaired tissue uptake and retention of these amino acids in ASD. For modified amino acids, only increased CMA remained significantly increased in plasma for children with ASD. This may relate to proteolysis of plasma proteins and potentially other proteins of increased CMA residue content in ASD. For modified amino acids in urine, urinary excretions of oxidative damage markers, DT and GSA free adducts, were increased in children with ASD after correction for multiple analytes. This may relate to proteolysis of plasma proteins and other proteins with increased oxidative damage and DUOXcatalyzed modification in ASD. The amino acid metabolome in plasma and urine has been explored previously for biomarkers of ASD [7, 45-47]. We confirmed the reported minor increase in plasma arg in ASD, compared to healthy controls, but significance was lost after correction for multiple measurements [48].

Pyrraline is an AGE sourced only from food [49]. Increased urinary pyrraline is indicative of increased food consumption and/or permeability of the gastrointestinal tract to pyrraline. The positive correlation of pyrraline with CML, MG-H1, CMA, DT, and GSA free adducts in urine suggests that increase of these free adducts may be partly due to food consumption.

Exploring changes in renal CL of amino acids provides insight in functional activity of amino acid transporters in the renal tubular epithelium. The deduction of CL herein was an indirect measure based on estimates of urinary analyte/creatinine ratio rather than urinary analyte excretion rate determined in urine collection made over a fixed time interval, usually $24 \mathrm{~h}$. This was done because of difficulties in timed collection of urine in children [50]. Decreased $\mathrm{CL}$ relates to increased tubular reuptake and increased amino acid transporter activity. Decreased CL of arg and CMA likely reflects increased reuptake of arg and CMA. Arg uptake by the tubular epithelium is mediated by neutral and basic amino acid transport protein rBAT and solute carrier 7, member $9\left(\mathrm{~b}^{0,+} \mathrm{AT}\right)$ [apical uptake] and CD98 heavy subunit (CD98hs) $/ y+L A T-2$ (solute carrier family 7 member 6) and CD98hs/y+LAT-1 (solute carrier family 7 member 7) complexes [basolateral transport] [51] and this likely mediates renal tubule uptake of arginine derivative CMA too (Fig. 6b). Homozygous mutations of SLC7A5 gene were associated with ASD. SLC7A5 encodes protein hLAT-1 which, together with CD98hs, form the large neutral amino acid transporter involved in maintaining normal levels of brain branched chain amino acids in the brain [52]. Dysfunction of hLAT-1, also found in the renal tubular epithelium in complex with CD98hs [51], may leave the latter more available for complexation with $y+L A T-1$ and $y+L A T-2$ and drive increased reuptake and decreased $\mathrm{CL}$ of arginine and CMA. In addition, rare holomorphic variants in males of amino acid transporter CAT-3 were associated with ASD [15]. Disturbance in arginine transporter function may be a common feature of ASD and measure of CL of arginine is an accessible biomarker of this.

Combination of AGE and DT residue content of plasma protein in Algorithm-1 and this combined with G-H1 and GSA free adducts in Algorithm-3 gave the best diagnostic performance for detection of ASD from the analytes determined herein. The absence of conventional, unmodified amino acids from optimum features of the diagnostic algorithms suggests that assay of trace level, AGE and oxidised amino acid residues of plasma protein and free adducts in plasma provides a diagnostic advantage which has not been hitherto explored. It also suggests that AGE and oxidation proteotoxic stress may underly the development of ASD, at least in part. Protein glycation and oxidation adducts from dietary protein contribute to levels of 
plasma and urinary glycation and oxidation free adducts; whereas glycation and oxidation adduct residues of protein reflect rates of endogenous glycation and oxidation of protein in mainly the vascular compartment. The dominance of plasma protein AGE and oxidation adducts in Algorithm-1 and the modest improvement by addition of plasma G-H1 and GSA free adducts (Algorithm-3) may indicate that there is limited influence of dietary glycated and oxidized proteins to the development of ASD. Rather, challenge to proteostasis by changes in endogenous protein modification by AGEs and DT may contribute to the development of ASD.

\section{Conclusions}

We identified changes in plasma protein glycation and oxidation markers; increased CML, CMA, and DT and decreased 3DG-H that combined in an algorithm gave improved diagnostic performance over other approaches. Increased levels of DT may indicate induction of increased DUOX activity linked to gut mucosa dysfunction. Disturbance of renal handling of arginine and CMA may indicate dysfunctional arginine transporter function common in ASD. Further clinical validation of plasma protein CML, CMA, DT, and 3DG-H may provide improved diagnosis of ASD. For future studies, we suggest firstly validation of the current findings in an independent clinical study group. Thereafter, priorities are investigation of the biomarkers in children younger than 5 years old to assess their ability to improve diagnosis at earlier stages of ASD development, assessment of the biomarkers in prospective studies for prediction of risk of progression to severe symptoms, study of the association of genetic polymorphisms of DUOX and arginine transporters with clinical ASD, preclinical functional genomics of DUOX and arginine transporters with an ASD-like phenotype, and assessment of the specificity of the algorithms for ASD versus other psychiatric conditions.

\section{Additional file}

Additional file 1: Table S1. Mass spectrometric multiple reaction monitoring detection of protein glycation, oxidation and nitration adducts and amino acids. Table S2. Correlation analysis - plasma protein glycation, oxidation and nitration adduct residues. Table $\mathbf{S 3}$. Correlation analysis plasma protein glycation, oxidation and nitration free adducts. Table S4. Correlation analysis - plasma amino acids. Table S5. Correlation analysis urinary protein glycation, oxidation and nitration free adducts. Table S6. Correlation analysis - Urinary amino acids. Table S7. Confusion matrix of algorithm to identify autistic spectrum disorder. (DOCX $80 \mathrm{~kb}$ )

\section{Abbreviations}

3-DG: 3-Deoxyglucosone; 3DG-H: Hydroimidazolone AGEs derived from 3deoxyglucosone; 3-NT: 3-Nitrotyrosine; AASA: a-Aminoadipic semialdehyde; ADOS: Autism diagnostic observation schedule; AGE: Advanced glycation endproduct; ASD: Autism spectrum disorder; AUROC: Area under-the-curve of receiver operating characteristic plot; $b^{0,+} A T$ : Solute carrier 7 , member 9; CARS: Childhood autism rating scale; CAT-3: Cationic amino acid transporter-3;
CD98hs: Cluster of differentiation heavy subunit; CEL: $N_{\varepsilon}$-(1-carboxyethyl)lysine; $\mathrm{CL}$ : Renal clearance; CMA: $N_{\omega}$-carboxymethylarginine; CML: $N_{\varepsilon}$-carboxymethyllysine; DT: Dityrosine; DUOX: Dual oxidase; EDTA: Ethylenediaminetetra-acetic acid; FL: $N_{\varepsilon}$-fructosyl-lysine; G-H1: Hydroimidazolone AGE derived from glyoxal; GSA: Glutamic semialdehyde; GSP: Glucosepane; hLAT-1: Large neutral amino acid transporter subunit-1; LC-MS/MS: Liquid chromatography-tandem mass spectrometry; Leiter-R: Leiter international performance scale-revised; MG: Methylglyoxal; MG-H1: Hydroimidazolone AGE derived from methylglyoxal MOLD, methylglyoxal-derived lysine crosslink; MRM: Multiple reaction monitoring; NFK: N-Formylkynurenine; PEP-3: Psychoeducational profile-3; rBAT: Neutral and basic amino acid transport protein; ROS: Reactive oxygen species; SLC7A5: Solute carrier family 7, member 5; SVM: Support vector machines; TD: Typically developing; UPR: Unfolded protein response; y+LAT-

1: Solute carrier family 7 member 7; $y+$ LAT-2: Solute carrier family 7 member 6

\section{Acknowledgements}

We thank all the subjects recruited and their parents for agreeing to participate in this study.

\section{Funding}

This work received funding from Warwick Impact Fund award to NR and funding from Fondazione del Monte di Bologna e Ravenna, Italy, and from Fondazione Nando Peretti, Rome, Italy, to M.M.

\section{Availability of data and materials}

Analytical data produced in this study may be obtained from the corresponding author

\section{Authors' contributions}

MM, PMA, AG, PJT, and NR designed the research; PV and AP chose the autistic and the control subjects, carried out the clinical evaluation, and supervised the blood withdrawal and urine collection; $A B$ organized the handling of biological samples, performed some preliminary experimental procedures, and kept the records; AA and SP analyzed the clinical samples and extracted analytical data, AG, KR, PJT, and NR analyzed the data and checked the data extraction; PJT, NR, MM, and PMA wrote the manuscript. All authors read, edited, and approved the final manuscript.

\section{Ethics approval and consent to participate}

The study was approved by the Unified Ethics Committee of Bologna, Imola and Ferrara (CE BIF); project number 13062. The experiments conformed to the principles set out in the World Medical Association Declaration of Helsinki. Whole blood and urine samples were collected from children with written informed consent of a parent.

\section{Consent for publication}

Written consent to publish individual children's details (Table 1) was given by their parent or legal guardian.

\section{Competing interests}

The authors declare that they have no competing interests.

\section{Publisher's Note}

Springer Nature remains neutral with regard to jurisdictional claims in published maps and institutional affiliations.

\section{Author details}

${ }^{1}$ Warwick Medical School, University of Warwick, Clinical Sciences Research Laboratories, University Hospital, Coventry, UK. ${ }^{2}$ Department of Experimental, Diagnostic and Specialty Medicine, School of Medicine, University of Bologna, Via Belmeloro 8, 40126 Bologna, Italy. ${ }^{3}$ Department of Computer Science, University of Birmingham, Birmingham, UK. ${ }^{4}$ Don Carlo Gnocchi Foundation ONLUS, IRCCS "S. Maria Nascente", Via Alfonso Capecelatro 66, 20148 Milan, Italy. ${ }^{5}$ Child Neurology and Psychiatry Unit, IRCCS Institute of Neurological Sciences, Via Altura, 3, 40139 Bologna, Italy. ${ }^{6}$ Department of Biomedical and Neuromotor Sciences, University of Bologna, Via Altura 3, 40139 Bologna, Italy. ${ }^{7}$ Zeeman Institute for Systems Biology \& Infectious Disease Epidemiology Research, Senate House, University of Warwick, Coventry CV4 7AL, UK. ${ }^{8}$ Research Technology Platform-Proteomics, University of Warwick, Coventry, UK. 


\section{Received: 25 August 2017 Accepted: 19 December 2017}

\section{Published online: 19 February 2018}

\section{References}

1. American-Psychiatric-Association. Diagnostic and statistical manual of mental disorders. Washington, DC: American Psychiatric Publishing; 2013.

2. Walsh $P$, Elsabbagh $M$, Bolton $P$, Singh I. In search of biomarkers for autism: scientific, social and ethical challenges. Nat Rev Neurosci. 2011;12(10):603-12.

3. Abruzzo PM, Ghezzo A, Bolotta A, Ferreri C, Minguzzi R, Vignini A, Visconti P, Marini M. Perspective biological markers for autism spectrum disorders: advantages of the use of receiver operating characteristic curves in evaluating marker sensitivity and specificity. Dis Markers. 2015;2015:329607.

4. Loke YJ, Hannan AJ, Craig JM. The role of epigenetic change in autism spectrum disorders. Front Neurol. 2015;6:18.

5. Scherer SW, Dawson G. Risk factors for autism: translating genomic discoveries into diagnostics. Hum Genet. 2011;130(1):123-48.

6. Momeni N, Bergquist J, Brudin L, Behnia F, Sivberg B, Joghataei MT, Persson BL. A novel blood-based biomarker for detection of autism spectrum disorders. Transl Psychiatry. 2012;2(3):e91.

7. Diémé B, Mavel S, Blasco H, Tripi G, Bonnet-Brilhault F, Malvy J, Bocca C, Andres CR, Nadal-Desbarats L, Emond P. Metabolomics study of urine in autism spectrum disorders using a multiplatform analytical methodology. J Proteome Res. 2015;14(12):5273-82.

8. Louros SR, Osterweil EK. Perturbed proteostasis in autism spectrum disorders. J Neurochem. 2016;139(6):1081-92.

9. Thornalley PJ, Rabbani N. Detection of oxidized and glycated proteins in clinical samples using mass spectrometry - a user's perspective. Biochim Biophys Acta. 2014;1840(2):818-29.

10. Melnyk S, Fuchs GJ, Schulz E, Lopez M, Kahler SG, Fussell JJ, Bellando J, Pavliv O, Rose S, Seidel L, et al. Metabolic imbalance associated with methylation dysregulation and oxidative damage in children with autism. J Autism Dev Disord. 2012;42(3):367-77.

11. Frye RE, DeLaTorre R, Taylor H, Slattery J, Melnyk S, Chowdhury N, James SJ. Redox metabolism abnormalities in autistic children associated with mitochondrial disease. Transl Psychiatry. 2013;3:e273.

12. Howsmon DP, Kruger U, Melnyk S, James SJ, Hahn J. Classification and adaptive behavior prediction of children with autism spectrum disorder based upon multivariate data analysis of markers of oxidative stress and DNA methylation. PLoS Comput Biol. 2017;13(3):e1005385.

13. Hetz C, Chevet E, Oakes SA. Proteostasis control by the unfolded protein response. Nat Cell Biol. 2015;17(7):829-38.

14. Janssens $S$, Pulendran B, Lambrecht BN. Emerging functions of the unfolded protein response in immunity. Nat Immunol. 2014;15(10):910-9.

15. Nava C, Rupp J, Boissel J-P, Mignot C, Rastetter A, Amiet C, Jacquette A, Dupuits $C$, Bouteiller D, Keren B, et al. Hypomorphic variants of cationic amino acid transporter 3 in males with autism spectrum disorders. Amino Acids. 2015;47(12):2647-58

16. Bala KA, Dogan M, Mutluer T, Kaba S, Aslan O, Balahoroglu R, Cokluk E, Ustyol L, Kocaman S. Plasma amino acid profile in autism spectrum disorder (ASD). European Review for Medical and Pharmacological Sciences. 2016; 20(5):923-9.

17. Schopler E, Reichler RJ, Renner BR. The childhood autism rating scale. Los Angeles: Western Psychological Services; 1994.

18. Ozonoff S, Heung K, Byrd R, Hansen R, Hertz-Picciotto I. The onset of autism: patterns of symptom emergence in the first years of life. Autism research: official journal of the International Society for Autism Research. 2008;1(6): 320-8.

19. Schopler E, Lansing MD, Reichler RJ, Marcus LM. Psychoeducational profile. 3rd ed. Torrance: Western Psychological Services; 2005.

20. Roid G, Miller LJ. Leiter international performance scale-revised: examiners manual. Wood Dale: Stoelting Co.; 1997.

21. Keys A. Epidemiological studies related to coronary heart disease: characteristics of men aged 40-59 in seven countries. Acta Medica Scandinavica. 1966;180:4-5.

22. Rabbani N, Shaheen F, Anwar A, Masania J, Thornalley PJ. Assay of methylglyoxal-derived protein and nucleotide AGEs. Biochem Soc Trans. 2014;42(2):511-7.

23. Ahmed U, Anwar A, Savage RS, Costa ML, Mackay N, Filer A, Raza K, Watts RA, Winyard PG, Tarr J, et al. Biomarkers of early stage osteoarthritis, rheumatoid arthritis and musculoskeletal health. Sci Rep. 2015;5:9259.
24. Ahmed U, Anwar A, Savage RS, Thornalley PJ, Rabbani N. Protein oxidation, nitration and glycation biomarkers for early-stage diagnosis of osteoarthritis of the knee and typing and progression of arthritic disease. Arthritis Res Ther. 2016;18(1):250.

25. Ahmed U, Anwar A, Savage RS, Costa ML, Mackay N, Filer A, Raza K, Watts RA, Winyard PG, Tarr J, et al. Biomarkers of early stage osteoarthritis, rheumatoid arthritis and musculoskeletal health. Sci Rep. 2015;5(9259):9251-7.

26. Breiman L. Random forests. Mach Learn. 2001;45(1):5-32.

27. Friedman J, Hastie T, Tibshirani R. Regularization paths for generalized linear models via coordinate descent. J Statistical Software. 2010;33(1):1-22.

28. Sajda P. Machine learning for detection and diagnosis of disease. Annu Rev Biomed Eng. 2006;8(1):537-65.

29. Rhemtulla M, Brosseau-Liard PE, Savalei V. When can categorical variables be treated as continuous? A comparison of robust continuous and categorical SEM estimation methods under suboptimal conditions. Psychol Methods. 2012;17(3):354-73.

30. Xue M, Weickert MO, Qureshi S, Ngianga-Bakwin K, Anwar A, Waldron M, Shafie A, Messenger D, Fowler M, Jenkins G, et al. Improved glycemic control and vascular function in overweight and obese subjects by glyoxalase 1 inducer formulation. Diabetes. 2016;65(8):2282-94.

31. Margarson MP, Soni N. Serum albumin: touchstone or totem? Anaesthesia. 1998;53(8):789-803.

32. Knecht KJ, Dunn JA, McFarland KF, McCance DR, Lyons TJ, Thorpe SR, Baynes JW. Effect of diabetes and aging on carboxymethyllysine levels in human urine. Diabetes. 1991;40(2):190-6.

33. Chauhan A, Chauhan V, Brown WT, Cohen I. Oxidative stress in autism: increased lipid peroxidation and reduced serum levels of ceruloplasmin and transferrin-the antioxidant proteins. Life Sci. 2004;75(21):2539-49.

34. Ming X, Stein TP, Brimacombe M, Johnson WG, Lambert GH, Wagner GC. Increased excretion of a lipid peroxidation biomarker in autism. Prostaglandins Leukot Essent Fat Acids. 2005;73(5):379-84.

35. Ghezzo A, Visconti P, Abruzzo PM, Bolotta A, Ferreri C, Gobbi G, Malisardi G, Manfredini S, Marini M, Nanetti L, et al. Oxidative stress and erythrocyte membrane alterations in children with autism: correlation with clinical features. PLoS One. 2013;8(6):14.

36. Lévigne D, Modarressi A, Krause K-H, Pittet-Cuénod B. NADPH oxidase 4 deficiency leads to impaired wound repair and reduced dityrosinecrosslinking, but does not affect myofibroblast formation. Free Radic Biol Med. 2016;96:374-84.

37. Ha E-M, Lee K-A, Seo YY, Kim S-H, Lim J-H, Oh B-H, Kim J, Lee W-J. Coordination of multiple dual oxidase-regulatory pathways in responses to commensal and infectious microbes in drosophila gut. Nat Immunol. 2009; 10(9):949-57.

38. Bae YS, Choi MK, Lee W-J. Dual oxidase in mucosal immunity and hostmicrobe homeostasis. Trends Immunol. 2010;31(7):278-87.

39. Chang S, Linderholm A, Franzi L, Kenyon N, Grasberger H, Harper R. Dual oxidase regulates neutrophil recruitment in allergic airways. Free Radic Biol Med. 2013;65:38-46.

40. Mussap M, Noto A, Fanos V. Metabolomics of autism spectrum disorders: early insights regarding mammalian-microbial cometabolites. Expert Rev Mol Diagn. 2016;16(8):869-81.

41. Delpierre G, Rider MH, Collard F, Stroobant V, Vanstapel F, Santos H, Van Schaftingen E. Identification, cloning, and heterologous expression of a mammalian fructosamine-3-kinase. Diabetes. 2000;49(10):1627-34.

42. Lal S, Randall WC, Taylor AH, Kappler F, Walker M, Brown TR, Szwergold BS. Fructose-3-phosphate production and polyol pathway metabolism in diabetic rat hearts. Metabolism. 1997:46(11):1333-8.

43. Thornalley PJ, Langborg A, Minhas HS. Formation of glyoxal, methylglyoxal and 3-deoxyglucosone in the glycation of proteins by glucose. BiochemJ. 1999;344(1):109-16.

44. Baba SP, Barski OA, Ahmed Y, O'Toole TE, Conklin DJ, Bhatnagar A, Srivastava S. Reductive metabolism of AGE precursors: a metabolic route for preventing AGE accumulation in cardiovascular tissue. Diabetes. 2009;58(11): 2486-97.

45. Ming X, Stein TP, Barnes V, Rhodes N, Guo L. Metabolic perturbance in autism spectrum disorders: a metabolomics study. J Proteome Res. 2012; 11(12):5856-62.

46. West PR, Amaral DG, Bais P, Smith AM, Egnash LA, Ross ME, Palmer JA, Fontaine BR, Conard KR, Corbett BA, et al. Metabolomics as a tool for discovery of biomarkers of autism spectrum disorder in the blood plasma of children. PLoS One. 2014;9(11):e112445. 
47. Gevi F, Zolla L, Gabriele S, Persico AM. Urinary metabolomics of young Italian autistic children supports abnormal tryptophan and purine metabolism. Molecular Autism. 2016;7(1):47.

48. Kuwabara H, Yamasue H, Koike S, Inoue H, Kawakubo Y, Kuroda M, Takano Y, Iwashiro N, Natsubori T, Aoki Y, et al. Altered metabolites in the plasma of autism spectrum disorder: a capillary electrophoresis time-of-flight mass spectroscopy study. PLoS One. 2013;8(9):e73814.

49. Foerster A, Henle T. Glycation in food and metabolic transit of dietary AGEs (advanced glycation end-products): studies on the urinary excretion of pyrraline. BiochemSocTrans 2003; 31:1383-1385.

50. Schwartz GJ, Work DF. Measurement and estimation of GFR in children and adolescents. Clin J Am Soc Nephrol. 2009;4(11):1832-43.

51. Broer S. Amino acid transport across mammalian intestinal and renal epithelia. Physiol Rev. 2008;88(1):249-86.

52. Tărlungeanu DC, Deliu E, Dotter CP, Kara M, Janiesch PC, Scalise M,

Galluccio M, Tesulov M, Morelli E, Sonmez FM, et al. Impaired amino acid transport at the blood brain barrier is a cause of autism spectrum disorder. Cell. 2016;167(6):1481-94. e1418

Submit your next manuscript to BioMed Central and we will help you at every step:

- We accept pre-submission inquiries

- Our selector tool helps you to find the most relevant journal

- We provide round the clock customer support

- Convenient online submission

- Thorough peer review

- Inclusion in PubMed and all major indexing services

- Maximum visibility for your research

Submit your manuscript at www.biomedcentral.com/submit
Biomed Central 